\title{
Tumour necrosis factor-alpha gene promoter polymorphism and decreased insulin resistance
}

\author{
C.P. Day ${ }^{1}$, J Grove ${ }^{2}$, A. K. Daly ${ }^{2}$, M.W. Stewart ${ }^{1}$, P.J. Avery ${ }^{3}$, M. Walker ${ }^{1}$ \\ ${ }^{1}$ Department of Medicine, University of Newcastle upon Tyne, UK \\ ${ }^{2}$ Department of Pharmacological Sciences, University of Newcastle upon Tyne, UK \\ ${ }^{3}$ Department of Statistics, University of Newcastle upon Tyne, UK
}

\begin{abstract}
Summary Insulin resistance is a feature of non-diabetic relatives of non-insulin-dependent diabetic (NIDDM) families. Tumour necrosis factor-alpha $(\mathrm{TNF} \alpha)$ expression is linked with insulin resistance, and is under strong genetic control. We examined the relationship between insulin resistance and two polymorphisms of the TNF $\alpha$ promoter region (positions -238 and --308). Non-diabetic relatives $(n=123)$ of NIDDM families and control subjects $(n=126)$ with no family history of diabetes were studied. Insulin resistance was determined by homeostasis model assessment (HOMA) and short insulin tolerance test (ITT), and genotyping was by restriction digest. The -238 polymorphism (TNFA- $A$ allele) was carried by 14 relatives and 11 control subjects, and all were heterozygotes. To examine the relationship between the -238 polymorphism and insulin resistance independent of potentially confounding factors, the relatives with the TNFA- $A$ allele were individually pair-matched for age, sex, waist-hip ratio, body mass index, and glucose tolerance with relatives
\end{abstract}

homozygous for the wild-type allele. Relatives with the TNFA- $A$ allele had decreased insulin resistance (HOMA index: 2.0, 3.6 \pm 2.1 [means \pm SD of differences], $p=0.03$ ), and this was true for comparable pair-matched control subjects (HOMA index: 1.1, $1.9 \pm 0.8, p=0.01)$. Combining relative $(n=7)$ and control $(n=4)$ pairs that had undergone an ITT, subjects with the TNFA- $A$ allele had an increased $\mathrm{K}_{\text {ITT }}$ $(3.8,3.0 \pm 1.0 \% / \mathrm{min}, p=0.04)$ similarly indicating decreased insulin resistance. There was no significant relationship between the -308 polymorphism and insulin resistance. We conclude that the TNFA-A allele is associated with decreased insulin resistance as assessed by two independent methods, and may protect against the future development of NIDDM in susceptible individuals. [Diabetologia (1998) 41: 430-434]

Key words Tumour necrosis factor-alpha, insulin resistance, polymorphism, gene promoter, relatives, family.
Decreased insulin action in skeletal muscle (insulin resistance) is a key feature of non-insulin-dependent diabetes mellitus (NIDDM) and obesity. The mecha-

\section{Received: 8 September 1997 and in revised form: 13 November} 1997

Corresponding author: Dr M. Walker, The Medical School, Framlington Place, Newcastle upon Tyne NE2 4HH, UK Abbreviations: TNFa, Tumour necrosis factor-alpha; TNFA-A allele, $\mathrm{G} \rightarrow \mathrm{A}$ substitution at position $-238 ;$ TNF2 allele, $\mathrm{G} \rightarrow \mathrm{A}$ substitution at position -308; MHC, major histocompatibility complex; HOMA, homeostasis model assessment; ITT, insulin tolerance test; NEFA, non-esterified fatty acids; CV, coefficient of variation. nisms underlying the development of insulin resistance are not clearly defined but recent interest has focused on tumour necrosis factor-alpha $(\mathrm{TNF} \alpha)$. Adipose tissue TNF $\alpha$ expression is increased in human obesity [1], and is closely correlated with circulating insulin levels which serve as an index of insulin resistance [1]. TNF $\alpha$ has also been shown to be expressed in skeletal muscle, and again this is increased in muscle from insulin resistant subjects [2]. More recently it was reported that obese mice homozygous for a targeted null mutation in the TNF $\alpha$ gene were significantly less insulin resistant than normal obese mice [3]. These observations strongly suggest that $\mathrm{TNF} \alpha$ impairs insulin action, and the mechanism seems to 
involve decreased insulin receptor tyrosine kinase activity [4].

The mechanisms by which TNF $\alpha$ expression is altered in insulin resistant states has not been identified. However, recent interest has focused on the relationship between polymorphisms of the gene encoding TNF $\alpha$ (TNFA) and susceptibility to conditions under which TNF $\alpha$ is considered to play an important pathogenic role. Two polymorphisms have been identified in the TNFA promoter. The first is a $\mathrm{G} \rightarrow \mathrm{A}$ substitution at position -308 [5], designated the TNF2 allele, which has been shown to increase transcription in in vitro expression studies [6], and has been linked with increased susceptibility to cerebral malaria [7]. The second polymorphism is a $\mathrm{G} \rightarrow \mathrm{A}$ substitution at position -238 [8], designated the TNFA- $A$ allele, which has been associated with susceptibility to pulmonary tuberculosis [9] and alcoholic liver disease [10]. This polymorphism lies within a putative $\mathrm{Y}$ box, a regulatory motif typical of the promoter region of MHC class II genes [8], although, as yet, no in vitro expression studies have been performed to examine its functional relevance.

A recent study in NIDDM patients showed no difference in the frequencies of the TNF2 and TNFA- $A$ alleles compared to healthy control subjects [11]. However, this study does not exclude the possibility that $\mathrm{TNF} \alpha$ promoter polymorphisms might influence $\mathrm{TNF} \alpha$ expression and thereby contribute to the severity of the insulin resistant phenotype. In NIDDM, insulin resistance is the result of a combination of primary inherited defects and secondary metabolic changes such as chronic hyperglycaemia and hypertriglyceridaemia. To limit the secondary metabolic influences, we have studied non-diabetic relatives of NIDDM families who have an inherited basis for their increased risk of diabetes [12]. Importantly, insulin resistance is an early metabolic feature of the relatives [13] and is a predictor for the progression to diabetes [14]. The purpose of this study, therefore, was to examine the relationship between the two $\mathrm{TNF} \alpha$ promoter polymorphisms and insulin resistance in non-diabetic relatives of NIDDM families and control subjects with no family history of diabetes.

\section{Subjects and methods}

We recruited 123 non-diabetic first degree relatives (age 20-65 years) from 45 NIDDM families of North European extraction with two or more living NIDDM patients, and 126 non-diabetic control subjects matched for age, sex and ethnic background and with no family history of diabetes. The control subjects were randomly selected from a population of over 1000 residents of the Newcastle and North Tyneside District that in turn had been selected from the Family Health Services Authority Register for a health survey conducted by the Department of Epidemiology, University of Newcastle upon
Tyne. Ethnicity was based upon both parents being of north European origin. None of the subjects were taking agents known to influence lipid or glucose metabolism. Informed written consent was obtained from all subjects and the study was approved by the Newcastle and North Tyneside District ethics committee.

Subjects underwent a $75 \mathrm{~g}$ oral glucose tolerance test, and newly diagnosed diabetic subjects were excluded from further analysis. Body mass index and waist-hip ratios were assessed by standard methods. Basal insulin resistance was determined using fasting insulin and glucose concentrations by homeostasis model assessment (HOMA) [15]. Subjects were invited to have a short insulin tolerance test (ITT) on a separate day to examine whole body insulin sensitivity [16]. Following an overnight fast, soluble insulin $(0.05 \mathrm{U} / \mathrm{kg})$ was given as an i.v. bolus and arterialised blood glucose concentrations were determined at $1 \mathrm{~min}$ intervals from 3 to $15 \mathrm{~min}$. Insulin sensitivity $\left(\mathrm{K}_{\mathrm{ITT}}\right)$ was derived from the slope of the regression of log glucose concentration against time [16]. Both the HOMA index $(r=0.88, p<0.0001)[15]$ and the $\mathrm{K}_{\mathrm{ITT}}$ value $(r=0.86$, $p<0.01)[16]$ have been shown to correlate strongly with the index of insulin resistance derived from the hyperinsulinaemic euglycaemic clamp, the widely agreed "gold standard" for in vivo determination of insulin resistance.

Glucose concentrations were measured by the glucose oxidase method (inter-assay CV $3.5 \%$ ) and serum insulin concentrations by specific enzyme immunoassay (inter-assay $\mathrm{CV}$ $4.8 \%$ at $34 \mathrm{pmol} / \mathrm{l}$ : DAKO Diagnostics Ltd, Ely, UK). Fasting serum triglyceride (inter-assay CV $2.4 \%$ ) and non-esterified fatty acid (NEFA) (inter-assay CV 3.0\%) concentrations were measured by centrifugal enzymatic analysis (Wako, Neuss, Germany). Fasting serum leptin concentrations were measured by radioimmunoassay (inter-assay $\mathrm{CV} 5.9 \%$ at 18 ng/ml: Linco Research Inc., St. Charles, Missouri, USA).

Genotyping. Both TNF $\alpha$ polymorphisms were detected using primers containing a single base-pair mismatch adjacent to the polymorphic site in order to introduce a restriction site into the wild-type nucleotide sequences after amplification. Three primers were prepared: A1 $=5^{\prime}$-ATCTGGAGGAAGCGGTAGTG; M1 = 5'-AATAGGTTTTGAGGGCCATG (contains a mismatch [underlined] corresponding to $G$ at position -313) and $M 2=5^{\prime}-A G A-$ AGACCCCCCTCGGAACC (contains a mismatch [underlined] corresponding to $\mathrm{T}$ at position -240). Primers A1 and M1 were used to amplify fragments containing the -308 polymorphism and primers A1 and M2 to amplify fragments containing the -238 polymorphism. DNA samples were amplified in $50 \mu \mathrm{l}$ of $\mathrm{KCl}$ reaction buffer (Bioline, London, UK) containing $200 \mu \mathrm{mol} / 1 \mathrm{dNTP}, 0.25 \mu \mathrm{mol} / 1$ primer(s), $1 \mu \mathrm{g}$ of DNA sample and 2 units of Taq polymerase (Bioline) for 35 cycles at $94^{\circ} \mathrm{C}$ for $1 \mathrm{~min}, 59^{\circ} \mathrm{C}$ for $1 \mathrm{~min}$ and $70^{\circ} \mathrm{C}$ for $45 \mathrm{~s}$ followed by 1 cycle at $70^{\circ} \mathrm{C}$ for $10 \mathrm{~min}$. The PCR products were digested at $37^{\circ} \mathrm{C}$ with $\mathrm{Nco}$ I to detect the -308 polymorphism and MspI to detect the -238 polymorphism and examined by $10 \%$ acrylamide and $4 \%$ agarose gel electrophoresis, respectively.

Statistical analysis. The HOMA index has a skewed distribution and so the data for the study populations are presented as the medians and interquartile ranges, and comparisons were made using the Mann Whitney U-test. Comparison of the pair-matched subject data was by paired $t$-test, and as the differences for each variable were approximately normally distributed, the data are presented as means \pm SD of the differences. All analyses were conducted using the Minitab Statistical Package. 
Table 1. Pair matched comparison of subjects with the $T N F A-A$ and wild-type alleles, for relatives and control subjects

\begin{tabular}{|c|c|c|c|c|c|c|c|c|}
\hline & \multicolumn{4}{|c|}{ Control subjects } & \multicolumn{4}{|l|}{ Relatives } \\
\hline & $T N F A-A$ & Wild-type & $\begin{array}{l}\text { SD of } \\
\text { differences }\end{array}$ & $p$ value & $T N F A-A$ & Wild-type & $\begin{array}{l}\text { SD of } \\
\text { differences }\end{array}$ & $p$ value \\
\hline Male:female & $4: 7$ & $4: 7$ & - & - & $9: 5$ & $9: 5$ & - & - \\
\hline Age (years) & 38 & 37 & 7 & 0.49 & 36 & 36 & 8 & 0.97 \\
\hline Body mass index $\left(\mathrm{kg} / \mathrm{m}^{2}\right)$ & 22.8 & 23.3 & 1.7 & 0.30 & 26.6 & 26.9 & 0.9 & 0.30 \\
\hline Waist-hip ratio & 0.82 & 0.80 & 0.05 & 0.10 & 0.86 & 0.87 & 0.04 & 0.48 \\
\hline $2 \mathrm{~h}$ blood glucose $(\mathrm{mmol} / \mathrm{l})$ & 5.2 & 4.9 & 1.2 & 0.32 & 5.0 & 5.4 & 1.8 & 0.26 \\
\hline Fasting triglyceride $(\mathrm{mmol} / \mathrm{l})$ & 1.0 & 1.1 & 1.1 & 0.40 & 1.1 & 1.2 & 0.9 & 0.57 \\
\hline Fasting NEFA (mmol/l) & 0.56 & 0.60 & 0.30 & 0.39 & 0.53 & 0.50 & 0.27 & 0.64 \\
\hline Fasting leptin (ng/ml) & 7.9 & 10.9 & 8.5 & 0.33 & 9.9 & 9.5 & 4.1 & 0.76 \\
\hline HOMA index & 1.1 & 1.9 & 0.8 & 0.01 & 2.0 & 3.6 & 2.1 & 0.03 \\
\hline
\end{tabular}

Data presented as means and SD of differences

Table 2. Pair matched comparison of subjects with the TNFA$A$ and wild-type alleles, for relative $(n=7)$ and control $(n=4)$ pairs combined

\begin{tabular}{lllll}
\hline & $T N F A-A$ & Wild-type & $\begin{array}{l}\text { SD of } \\
\text { differences }\end{array}$ & $p$ value \\
\hline $\begin{array}{l}\text { Male:female } \\
\text { Age (years) }\end{array}$ & $8: 3$ & $8: 3$ & - & - \\
$\begin{array}{l}\text { Body mass index } \\
\left(\mathrm{kg} / \mathrm{m}^{2}\right)\end{array}$ & 24.7 & 24.9 & 1.6 & 0.75 \\
Waist-hip ratio & 0.86 & 0.85 & 0.06 & 0.39 \\
$\begin{array}{l}\text { 2 h blood glucose } \\
\text { (mmol/l) }\end{array}$ & 5.2 & 5.2 & 1.6 & 0.96 \\
$\begin{array}{l}\text { Fasting triglyceride } \\
\text { (mmol/l) }\end{array}$ & 1.2 & 1.2 & 1.1 & 0.79 \\
$\begin{array}{l}\text { Fasting NEFA } \\
\text { (mmol/l) }\end{array}$ & 0.60 & 0.52 & 0.34 & 0.45 \\
$\begin{array}{l}\text { Fasting leptin (ng/ml) } \\
8.9\end{array}$ & 7.7 & 3.9 & 0.23 \\
$\begin{array}{l}\text { HOMA index } \\
\mathrm{K}_{\text {ITT }} \text { (\%/min) }\end{array}$ & 1.7 & 2.5 & 1.1 & 0.03 \\
\hline
\end{tabular}

Data presented as means and SD of differences

\section{Results}

The TNFA- $A$ allele was found to be possessed by 11.4 and $8.7 \%$ of the relatives and control subjects, respectively, and all were heterozygotes. For the -308 polymorphism, 31 and $30 \%$ of the relatives and control subjects, respectively, were heterozygotes, while $1.6 \%$ of both subject groups were TNF2 homozygotes.

The HOMA index was decreased in the subjects with the TNFA- $A$ allele in the relative $(1.7 \pm 1.0-2.9$ vs $2.2 \pm 1.5-3.8[n=14$ vs 109$], p=0.06)$ and control subjects $(0.9 \pm 0.6-1.8$ vs $1.7 \pm 1.2-2.2$ [ $n=11$ vs 115 ], $p=0.01$ ). To examine the relationship between the -238 polymorphism and insulin resistance independent of metabolic and anthropometric confounding factors, the relatives and control subjects with the TNFA- $A$ allele were individually pair-matched for age, sex, waist-hip ratio, body mass index and 2-h blood glucose concentrations with corresponding relatives (none related by family) and control subjects homozygous for the wild-type allele (Table 1). In addition, there were no significant differences in fasting NEFA, triglyceride and leptin levels between the pair-matched subjects within the relative and control subject groups. However, the relatives $(p=0.03)$ and control subjects $(p=0.01)$ with the TNFA- $A$ allele had significantly lower HOMA values (Table 1), indicating decreased insulin resistance. Of these 14 relative and 11 control matched pairs, 7 and 4 pairs, respectively, had undergone an ITT. As both relatives and control subjects with the TNFA-A allele showed a comparable decrease in insulin resistance based on the HOMA index, the relative and control pairs who had also been assessed by ITT were analysed together as shown in Table 2. As expected, the HOMA index remained significantly lower in the subjects with the $T N F A-A$ allele $(p=0.03)$, while the $\mathrm{K}_{\text {ITT }}$ value was significantly increased $(p=0.04)$ indicating decreased whole body insulin resistance. Thus, insulin resistance as assessed by two independent methods was decreased in the subjects with the TNFA-A allele compared with subjects homozygous for the wildtype allele.

There was no relationship between insulin resistance and the -308 polymorphism in the two subject groups (data not shown).

\section{Discussion}

We have shown that subjects with the polymorphism at position -238 of the TNF $\alpha$ promoter (TNFA- $A$ allele) have decreased insulin resistance, and this applies to non-diabetic relatives with a strong family history of NIDDM and control subjects with no family history of diabetes. The increasing evidence implicating TNF $\alpha$ in the pathogenesis of insulin resistance together with as yet indirect evidence that the TNFA- $A$ allele is associated with decreased $\mathrm{TNF} \alpha$ expression, suggests a causal link between the -238 TNFA polymorphism and the level of insulin resistance.

Two independent methods were used to examine insulin resistance; the HOMA index based upon fast- 
ing insulin and glucose concentrations [15], and the $\mathrm{K}_{\text {ITT }}$ value derived from the blood glucose response to a bolus of exogenous insulin [16]. Although these methods examine insulin resistance under different physiological conditions, significant correlations between HOMA and $\mathrm{K}_{\mathrm{ITT}}$ were evident in both the relative $(r=-0.58, p<0.0001)$ and control $(r=-0.61$, $p<0.0001)$ populations. Both methods showed that subjects with the TNFA- $A$ allele had decreased insulin resistance, and served to highlight the importance of the relationship. Insulin resistance is influenced by many factors, including circulating glucose [17] and NEFA [18] levels, and the size and distribution of the adipose tissue stores $[19,20]$. As shown in Table 1 , the process of pair-matching removed any important anthropometric and metabolic differences between the relative and control subjects carrying the TNFA-A allele and the corresponding homozygous wild-type subjects, and suggests that the differences in insulin resistance were not a secondary effect of TNF $\alpha$ genotype on these potentially confounding variables.

The most obvious explanation for the association between the TNFA- $A$ allele and decreased insulin resistance is that the -238 polymorphism is functionally important and leads to decreased TNF $\alpha$ gene expression and accordingly decreased impairment of insulin action. Recent evidence provides support for this proposal. First, possession of the TNFA- $A$ allele has been found to be associated with increased susceptibility to pulmonary tuberculosis [9] and impaired clearance of hepatitis B [21] both of which could reflect an impaired Th-1, cytotoxic $\mathrm{CD}^{+}{ }^{+} \mathrm{T}$-cell response which requires TNF $\alpha$ [22]. Second, while there is as yet no direct evidence that the variant allele is associated with altered gene transcription, position -238 is located within a sequence similar to the so-called Y box which is a regulatory motif typical of the promoter region of MHC class II genes [8]. Position -238 corresponds to a nucleotide site particularly conserved among TNFA Y boxes of different species and among different MHC class II genes [23]. In the mouse the TNFA promoter Y box binds an abundant nuclear factor and is involved in the baseline expression of the TNFA gene [24], while a single base pair substitution in the Y box of the $H L A-D Q A 1$ promoter has recently been shown to significantly decrease transcription [25]. Studies aimed at obtaining direct evidence for the effect of the -238 polymorphism on $\mathrm{TNF} \alpha$ expression are currently ongoing in our laboratory.

Alternative explanations for the association between the -238 polymorphism and insulin resistance are population stratification and linkage disequilibrium with other functionally relevant allelic variants of either the TNF $\alpha$ gene itself or neighbouring locii. Population stratification refers to the possibility that the TNFA-A heterozygotes come from a different and more insulin sensitive ethnic group. This can be overcome either by repeating the observation in other distinct populations or by looking for intrafamilial allelic association with tests such as the transmission disequilibrium test [26].

In both subject groups, we failed to identify an important relationship between the -308 polymorphism and insulin resistance. This is in keeping with other observations $[8,10]$ that there is no linkage disequilibrium between the -238 and -308 polymorphisms. However, an increased percentage of body fat and insulin resistance was recently reported in Spanish subjects with the TNF2 allele compared to TNF1 homozygotes [27]. The disparity between this and our study may reflect differences in study design and populations (northern and southern Europeans), but it is clear that further work is needed to define the relationships between the -238 and -308 polymorphisms and insulin resistance in other populations.

In conclusion, we have identified an important relationship between the TNFA- $A$ allele and decreased insulin resistance. As insulin resistance is a key predictor for the development of NIDDM in at risk non-diabetic relatives [14], the possession of this polymorphism may help to protect susceptible individuals from the progression to diabetes.

Acknowledgements. This work was funded by the Medical Research Council and British Diabetic Association. We thank Dr D. B. Humphriss, Sisters M. Brown and M. Miller, and Mrs L. Ashworth and her staff for technical support.

\section{References}

1. Hotamisligil GS, Arner P, Caro JF, Atkinson RL, Spiegelman BM (1995) Increased adipose tissue expression of tumour necrosis factor- $\alpha$ in human obesity and insulin resistance. J Clin Invest 95: 2409-2415

2. Saghizadeh M, Ong JM, Garvey WT, Henry RR, Kern PA (1996) The expression of TNF $\alpha$ by human muscle. J Clin Invest 97: 1111-1116

3. Uysal KT, Weisbrock SM, Marino MW, Hotamisligil GS (1997) Protection from obesity-induced insulin resistance in mice lacking TNF- $\alpha$ function. Nature 389: 610-614

4. Hotamisligil GS, Peraldi P, Budavari A, Ellis R, White MF, Spiegelman BM (1996) IRS-1-mediated inhibition of insulin receptor tyrosine kinase activity in TNF- $\alpha$ and obesityinduced insulin resistance. Science 271: 665-668

5. Wilson AG, de Vries N, Pociot F, di Giovine FS, van der Putte LBA, Duff GW (1993) An allelic polymorphism within the human tumour necrosis factor $\alpha$ promoter region is strongly associated with HLA A1,B8 and DR3 alleles. J Exp Med 177: 557-560

6. Wilson AG, Symons JA, McDowell TL, McDevitt, HO, Duff GW (1997) Effects of a polymorphism in human tumor necrosis factor $\alpha$ promoter on transcriptional activation. Proc Natl Acad Sci USA 94: 3195-3199

7. McGuire W, Hill AVS, Allsopp CEM, Greenwood BM, Kwiatkowski D (1994) Variation in the TNF- $\alpha$ promoter region associated with susceptibility to cerebral malaria. Nature 371: 508-511 
8. D' Alfonso S, Richiardi PM (1994) A polymorphic variation in a putative regulation box of the TNFA promoter region. Immunogenetics 39: 150-154

9. Ruwende C, McGuire W, Coleman E, et al. (1996) Association of a tumor necrosis factor promoter polymorphism with susceptibility to pulmonary tuberculosis. Clin Sci 90: 3P (Abstract)

10. Grove J, Daly AK, Bassendine MF, Day CP (1997) Association of a tumour necrosis factor promoter polymorphism with susceptibility to alcoholic steatohepatitis. Hepatology 26: $143-146$

11. Hamann A, Mantzoros C, Vidal-Puig A, Flier JS (1995) Genetic variability in the TNF- $a$ promoter is not associated with type II diabetes mellitus (NIDDM). Biochem Biophys Res Comm 211: 833-839

12. Kobberling J, Tillil H (1982) Empirical risk figures for first degree relatives of non-insulin dependent diabetics. In: Kobberling J, Tattersall R (eds) The genetics of diabetes mellitus. Academic Press, London, pp 201-209

13. Stewart MW, Humphriss DB, Berrish TS, et al. (1995) Features of syndrome $\mathrm{X}$ in first-degree relatives of NIDDM patients. Diabetes Care 18: 1020-1022

14. Martin BC, Warram JH, Krolewski AS, Bergman RN, Soeldner JS, Kahn CR (1992) Role of glucose and insulin resistance in development of type 2 diabetes mellitus: results of a 25 year follow up study. Lancet 340: 925-929

15. Matthews DR, Hosker JP, Rudenski AS, Naylor BA, Treacher DF, Turner RC (1985) Homeostasis model assessment; insulin resistance and B-cell function from fasting plasma glucose and insulin concentrations in man. Diabetologia 28: 412-419

16. Akinmokun A, Selby PL, Ramaiya K, Alberti KGMM (1992) The short insulin tolerance test for determination of insulin sensitivity: a comparison with the euglycaemic clamp. Diabet Med 9: 432-437

17. Yki-Jarvinen H (1990) Acute and chronic effects of hyperglycaemia on glucose metabolism. Diabetologia 33: 579-585
18. Ferrannini E, Barrett EJ, Bevilacqua S, De Fronzo RA (1983) Effect of fatty acids on glucose production and utilization in man. J Clin Invest 72: 1737-1747

19. Bonadonna RC, Groop L, Kraemer N, Ferrannini E, Del Prato S, De Fronzo RA (1990) Obesity and insulin resistance in man: a dose response study. Metabolism 39: 452-459

20. Kissebah AH (1991) Insulin resistance and visceral obesity. Int J Obesity 15 [Suppl 2]:109-115

21. Hohler T, Kruger A, Gerken G, Schneider PM, Meyer zum Buschenfelde K-H, Rittner C (1996) A TNF-alpha polymorphism is associated with chronic hepatitis B. J Hepatol 26[Suppl 1]:68 (Abstract)

22. Flesch IEA, Hess JH, Huang S, et al. (1995) Early interleukin 12 production by macrophages in response to mycobacterial infection depends on interferon gamma and tumor necrosis factor $\alpha$. J Exp Med 181: 1615-1621.

23. Benoist C, Mathis D (1990) Regulation of major histocompatibility complex class-II genes: X Y and other letters of the alphabet. Ann Rev Immunol 8: 681-715

24. Drouet C, Shakov AN, Jongeneel CV (1991) Enhancers and transcription factors controlling the inducibility of the tumor necrosis factor- $\alpha$ promoter in primary macrophages. J Immunol 147: 1694-1700

25. Haas JP, Kimura A, Truckenbrodt H, et al. (1995) Early onset pauciarticular juvenile chronic arthritis is associated with a mutation in the Y-box of the HLA-DQA1 promoter. Tissue Antigens 45: 317-321

26. Speilman RS, McGinnis RE, Ewens WJ (1993) Transmission test for linkage disequilibrium: the insulin gene region and insulin-dependent diabetes mellitus. Am J Hum Genet 52: 506-516

27. Fernandez-Real JM, Gutierrez C, Ricart C, et al. (1997) The TNF- $\alpha$ gene Nco I polymorphism influences the relationship among insulin resistance, percent body fat, and increased serum leptin levels. Diabetes 46: 1468-1472 